\section{Chernobyl fallout on Ioannina, Greece}

Sir-We have measured the $\gamma$-ray spectrum of the fallout from the Chernobyl located in northwestern Greece, nearly $1,500 \mathrm{~km}$ south-west of Chernobyl. We have examined air filters collected every $24 \mathrm{~h}$ since 29 April to monitor the $\gamma$ radiation activity, using an intrinsic germanium high-resolution detector, shielded to reduce background. The fallout probably reached loannina between 1 and 2 May, and the activity peaked on 5 May. After that we noticed a reduction of the air contamination, mainly due to local rains.

Figure 1 shows a typical $\gamma$-ray spectrum from one of our filters, the activity of which was measured three times at monthly intervals to estimate the halflives of the radionuclides present. From a number of spectra, 14 different nuclides were identified by their energy spectra and half-lives and 9 additional peaks in the spectral region between 50 and $800 \mathrm{KeV}$ remain unidentified.

In Table 1 the activity of each of the most prominent radioisotopes is characterized as very strong (VS), strong (S), weak (W) or very weak (VW), and the respective half-life as very long (VL), long (L) or short (S). The ${ }^{1: 1}$ I activity is defined 'strong' and its half-life as 'long'. Table 1 also lists the masses of fission decay products generated in the reactor'. Table 2 lists the energies of the unidentified lines.

From our air-filter measurements we conclude that: (1) the relative activities for the most prominent isotopes remained unchanged during most of the period nuclear reactor accident at Ioannina,

Table 1 Radioisotopes identified from air filters

\begin{tabular}{|c|c|c|c|}
\hline Isotope & Relative $\gamma$-activity & Half-life & $\begin{array}{l}\text { Mass of fission products } \\
\left(\mathrm{mg} \mathrm{MW} \mathrm{M}^{-1} \mathrm{day}^{-1}\right)\end{array}$ \\
\hline${ }^{95} \mathrm{Nb}$ & VW & VL & 0.33 \\
\hline${ }^{96} \mathrm{Mo}$ & W & $\mathrm{S}$ & 107.0 \\
\hline \multirow[t]{2}{*}{${ }^{103} \mathrm{Ru}$} & vS & VL & \multirow{4}{*}{65.4} \\
\hline & & & \\
\hline${ }^{1116} \mathrm{Ru}$ & W & VL & \\
\hline \multirow[t]{2}{*}{${ }^{129 \mathrm{~m}} \mathrm{Te}$} & VW & VL & \\
\hline & & & \multirow[t]{2}{*}{15.7} \\
\hline${ }^{1.32} \mathrm{Te}$ & S & S & \\
\hline${ }^{13 i} \mathrm{I}$ & $\mathrm{S}$ & $\mathrm{L}$ & \multirow[t]{3}{*}{5.86} \\
\hline${ }^{132} \mathrm{I}$ & $S$ & $\mathrm{~S}$ & \\
\hline${ }^{134} \mathrm{Cs}$ & $\mathrm{S}$ & VL & \\
\hline${ }^{136} \mathrm{Cs}$ & VW & $\mathrm{L}$ & \multirow[t]{2}{*}{90.4} \\
\hline${ }^{1.37} \mathrm{Cs}$ & $\mathrm{S}$ & VL & \\
\hline${ }^{141} \mathrm{~B} \mathrm{a}$ & W & $\mathrm{L}$ & 38.6 \\
\hline${ }^{141} \mathrm{La}$ & W & $\mathrm{S}$ & 39.8 \\
\hline${ }^{14 !} \mathrm{Ce}$ & VW & VL & 86.0 \\
\hline
\end{tabular}

between 1 and 10 May; (2) these activities are not what would be expected from the mass of fission products and their volatility. (3) We agree with Pringle et al. ' that the identified radioisotopes are ${ }^{215} \mathrm{U}$ fission decay products; however, we did not locate the isotopes ${ }^{15} \mathrm{Zr},{ }^{1+4} \mathrm{Ce},{ }^{127} \mathrm{Sb},{ }^{1115} \mathrm{Rh}$ and ${ }^{1+3} \mathrm{Ce}$. (4) The reactor operation time based on the ratio of ${ }^{1.37} \mathrm{Cs}$ to ${ }^{1.34} \mathrm{Cs}$ activity is $15 \%$ higher than that reported by Devell et al. ${ }^{3}$ using the same method. (5) Finally, a trace analysis using $\mathrm{X}$-ray energy spectrometry was inconclusive in locating $\mathrm{Sr}$ in our air filters.

The extreme conditions in the reactor core after the accident make it hard to know in what chemical compounds the radioisotopes appear in the radioactive cloud. Unfortunatly, information about core conditions before and during the accident is not yet available to us, and therefore we cannot verify our assumption

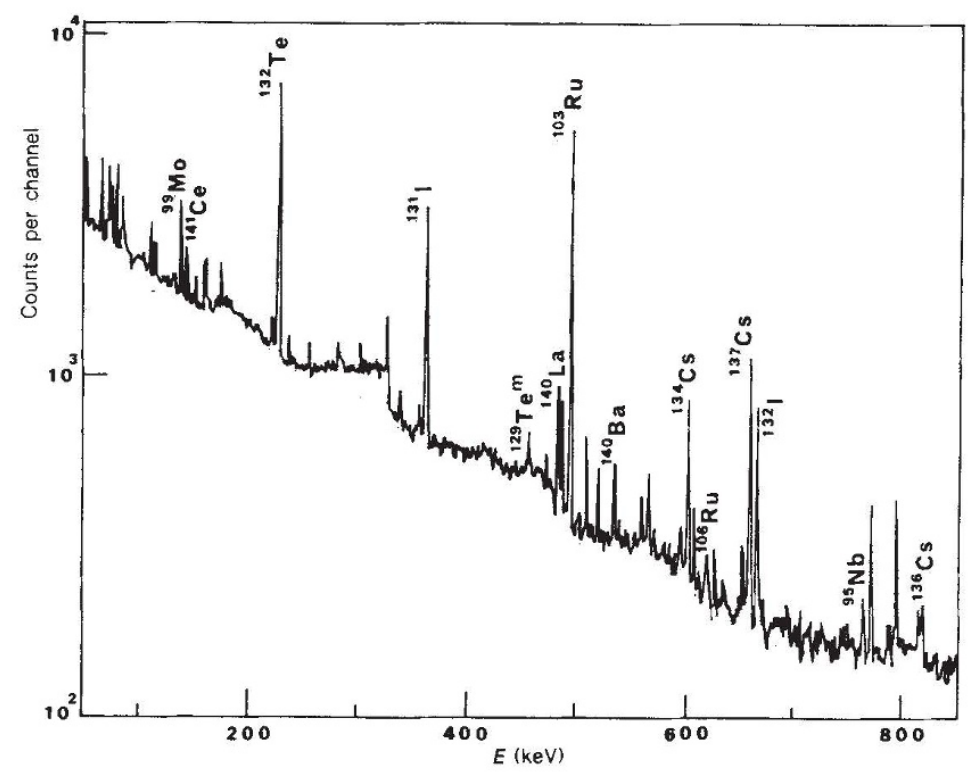

Fig. 1. A typical complex $\gamma$-ray spectrum obtained with an intrinsic Ge detector from an air filter.

\begin{tabular}{|ccc}
\hline \multicolumn{3}{c}{ Table 2 Unidentified spectral lines } \\
\hline $\begin{array}{c}\text { Energy } \\
(\mathrm{keV})\end{array}$ & Relative $\gamma$-activity & Half-life \\
223.4 & $\mathrm{VW}$ & $\mathrm{S}$ \\
239.2 & $\mathrm{VW}$ & $\mathrm{S}$ \\
257.4 & $\mathrm{VW}$ & $\mathrm{S}$ \\
358.4 & $\mathrm{~W}$ & $\mathrm{~L}$ \\
489.7 & $\mathrm{~W}$ & $\mathrm{~L}$ \\
511.6 & $\mathrm{~W}$ & $\mathrm{VL}$ \\
597.9 & $\mathrm{~W}$ & $\mathrm{~L}$ \\
653.9 & $\mathrm{~W}$ & $\mathrm{~S}$ \\
787.6 & $\mathrm{VW}$ & $\mathrm{S}$ \\
\hline
\end{tabular}

that the surprisingly high proportion of non-volatile nuclides (such as ${ }^{112} \mathrm{Ru}$ ) and the absence of volatile nuclides reflect the chemical compound which hosted the nuclides at the time of release to the atmosphere.

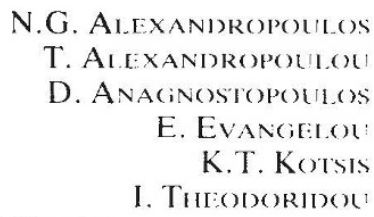

Department of Physics.

University of Ioaninina.

45332 Ioannina, Greece

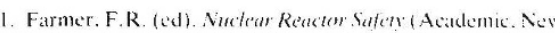
York. 1977).

2. Pringle, D.M. Vermeer W.J. \& Allen, K.W. Nuture 321 $5(1)(1956)$

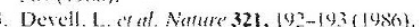

\section{The origins of the Earth's oceans}

SıR-Several mechanisms have been proposed for the origin of the Earth's oceans. such as the degassing of crustal rocks over geological time $i$ and the formation of impact produced atmosphere, including water, by accretion of planetesimals ${ }^{23}$ early during the Earth's formation. The available evidence suggests that sizeable oceans were present early in the Earth's history ${ }^{3}$ and that the early Solar System 